\title{
Article
}

\section{Optimal Path for Sustainable Retirement System in Malaysia}

\author{
Sim Ying Run ${ }^{1, \ddagger}$, Adem Kilicman ${ }^{1, \ddagger}$ \\ 1 Department of Mathematics, Faculty of Science, Universiti Putra Malaysia, Malaysia; \\ yingrunsim@gmail.com \\ 2 Institute for Mathematical Research, Universiti Putra Malaysia, Malaysia; akilic@upm.edu.my \\ * Correspondence: akilic@upm.edu.my; Tel.: +603-89466813 \\ $\ddagger$ These authors contributed equally to this work.
}

\begin{abstract}
This research aims to analyse the sustainability of retirement system and relevant optimal path to achieve sustainable post-retirement livings in Malaysia context. Focus of this study is put on Employees Provident Fund (EPF) which is mainly constituted by employees from private sector. EPF is a fully funded defined-contribution by both employees and employers. In this research, main variables used are contribution rate and retirement age based on relevant indexation of pension. For a sustainable retirement living, retirement benefits are expected to be in a maximisation function. Attempts to find sustainable retirement fund are via step-by-step mathematical calculation using formulas in Microsoft Excel and verification of the result with Excel Solver via Generalised Reduced Gradient (GRG) algorithm. Eventually, two-third retirement decision model is used to justify the sustainability of retirement fund other than justification using monthly household expenditure.
\end{abstract}

Keywords: Sustainable; defined-contribution; optimisation; present value; future value.

\section{Introduction}

Retirement system is designed to deliver decent living qualities and economic independence for the elderly [8]. According to Barr and Diamond, pension systems have multiple objectives and analysis is made by considering the pension system as a whole [1]. Its design influences labour market, economic growth, distribution of risk and distribution of income, and also generation and gender.

In Malaysia, two major types of retirement system are civil pension scheme and Employees Provident Fund (EPF). EPF is classified as defined-contribution (DC) pension system whereas civil pension scheme is considered to be defined-benefit (DB) pension system. DB pension is a pension system with the pension benefits are calculated based on a function of the worker's history of pensionable earnings and duration of service. DC pension is another pension system with the benefits are based on the accumulated value of assets for a person's pension. Benefits may be withdrawn either as a lump sum or as a sequence of withdrawals or even through purchase of an annuity. However, individual is required to bear the portfolio risk because a pure DC plan adjusts obligations to match with existing funds. [1]

Contribution to EPF is mandatory where its contribution rate is determined by the monthly wages of an employee. For examples, an employee who receives wages of RM 5,000 or below can opt for contribution of either $11 \%$ or $8 \%$ (until December 2017) of his monthly wages but his employer's contribution is $13 \%$ out of the employee's wages. However, employer's contribution is only $12 \%$ for those employees with wages exceeding RM 5,000. For civil service pension scheme, there is no contribution from employees. However, it is only eligible for employees with a minimum 10 years of civil service and minimum retirement age at 60 years. It is fully financed and supported by the government.

Apart from civil pension system and EPF pension system, there are other methods of savings for retirement income, such as Private Retirement Scheme (PRS) issued by asset management 
companies and insurance policies designed by insurance companies specifically for retirement planning. According to Yeoh, one of the major differences between insurance policy and PRS is insurance policy requires a consistent contribution of premium in an agreed lump sum amount or annuities while the latter allows contribution at any time with a minimum amount as agreed by PRS providers [20]. This shows that PRS has higher flexibility.

In Malaysia, retirement age is 60 years old as stated in Malaysian Labour Law. Statistic released by Department of Statistics Malaysia indicates that life expectancy at birth among Malaysia population increases to 74.7 years in 2016 as compared to 72.2 years as in 2000 [5]. Consumer price index (CPI) Malaysia has increased by 3.2\% from December 2016 to January 2017 by setting the CPI in 2010 as base year [6]. This shows the cost of living increases.

Thus, this study focuses on DC pension system in Malaysia by analysing the sustainability of funding for the elderly's retirement living as life expectancy and cost of livings increase. Sustainability is the capability of being maintained and supported for a period of time. Besides, sustainability is applied to the fiscal policies of government, public sector and pension system [15]. In the recent Occasional Studies in 2016, sustainability in public finance system refers to long-term ability of government in fulfilling the financial commitments [17].

In this paper, we find the sustainable retirement fund for EPF based on variation in retirement age and contribution rate according to indexation of pension. Indexation of pension includes longevity, growth of retirement fund, inflation rate and salary growth. The accumulated fund involves deposits made, growth on retirement fund and any withdrawals made. No unemployment is considered in the study.

In searching for suitable method of accomplishing this study, several papers are studied. We begin with Haberman and Zimbidis (2002), Pantelous and Zimbidis (2006), Pantelous and Zimbidis (2008), Gannon et al. (2014), Godínez-Olivares et al. (2015) and follow by Godínez-Olivares et al. (2016) $[9-12,18,19]$. We also study paper from MacDonald and Cairns (2011) on retirement decision model for DC retirement system [16]. We refer to equation on calculation of retirement fund and equation on optimisation of present value for retirement fund in [11] and two-third retirement decision model in [16] for mathematical modelling in Section 2.

In the following sections of this paper, Section 2 discusses mathematical model formed to apply in mathematical software. After that, we fit the model into EPF retirement system in Malaysia as found in Section 4. In Section 5, conclusion is made and future work of this paper is suggested.

\section{Mathematical Modelling}

We use nonlinear optimisation for a pension system. Variables are contribution rates, $c_{n}$ and retirement age, $x_{n, r}$ based on relevant indexation of pension, $\lambda$. Factors of longevity, $L_{x}$, salary growth, $g_{n}$, growth of retirement fund, $J_{n}$ and inflation rate, $\delta(0<\delta<1)$ are considered as indexation of pension.

In calculation of accumulated fund in an individual's account, we modify equation on dynamics of fund from [10] into Equation (1) using the similar concept.

$$
F_{n}=\left(1+J_{n}\right) F_{n-1}+c_{n} W_{n}\left(g_{n}, x_{n, r}\right)-B_{n}\left(x_{n, r}\right),
$$

where $F_{n}$ is the retirement fund for current year, $n, F_{n-1}$ is the retirement fund for previous year, $(n-1), W_{n}$ is the function of wages received in year $n, B_{n}$ refers to function of withdrawals in year $n$ when $x_{n, r} \geq 50, n$ is number of year in work. Accumulated fund at time $n$ is equal to the sum of accumulated fund of prior year and contribution made in $n$-th year after deduction of withdrawals made in $n$-th year (if any). Accumulated fund in prior years considers growth on retirement fund (dividend declared). 
Maximisation of present value for retirement fund at time $n$ is found using Equation (2) as follows.

$$
\max _{c_{n}, x_{n, r}, \lambda_{n}} \frac{F_{n}\left(c_{n}, g_{n}, x_{n, r}, \lambda_{n}, J_{n}\right)}{(1+\delta)^{n}}
$$

and, it is subjected to nonlinear constraints in Inequalities (3) and (4).

$$
\begin{aligned}
& c_{\text {min }} \leq c_{n} \leq c_{\text {max }}, x_{\text {min }, r} \leq x_{n, r} \leq x_{\text {max }, r}, \lambda_{\text {min }} \leq \lambda_{n} \leq \lambda_{\text {max }} \text {, } \\
& 0.61 \text { million } \leq F_{n} \leq 3.88 \text { million. }
\end{aligned}
$$

MacDonald and Cairns discovered that both OY model and two-third retirement decision model shared the same replacement ratio at $\frac{2}{3}$ which stimulated workers from age group of 55 to 70 to retire [16]. If the fund is found to satisfy the two-third replacement ratio in retirement decision model, the respective retirement age and contribution rate via suitable indexation of pension are considered to be at their optimal values. Hence, minimum retirement age, $x$ for two-third retirement decision model is shown in Equation (5).

$$
x=\min \left\{x: R R(t) \geq \frac{2}{3}\right\},
$$

where $R R(t)$ is the replacement ratio at time, $n=t$.

Thus, we check on the retirement fund for employees in age group of 55 to 70 whether they can achieve the target of two-third replacement ratio using the percentage of monthly retirement benefit over last drawn monthly salary. Percentage is found via Equation (6) as follows.

$$
\text { Percentage }=\frac{\text { Monthly retirement benefits }}{\text { Last drawn monthly salary }} \times 100 \% \text {. }
$$

Optimal value for contribution rate, retirement age based on relevant indexation of pension to achieve sustainable retirement system is found and then, we justify amount of accumulated fund based on suitable retirement decision model for sustainable post-retirement living.

\section{Numerical Computation}

There are two parts of calculations are involved, namely Part I and Part II in fitting the model in Section 2 into Malaysia's EPF system.

\subsection{Part I: Calculation of Upper Bound and Lower Bound of Retirement Funds}

In Part I, we find the upper bound and lower bound of retirement fund based on average salary data, $w_{\text {ave }}$ which equals RM 7,384 taken from iMoney Malaysia [13] and RM 2,463 from Department of Statistics Malaysia [4] with contribution rate, $c_{n}=23 \%$ (Salary $>$ RM 5,000) or 24\% (Salary $\leq$ RM $5,000)$ and $m$ is the number of month in a year.

For retirement at the age of 55, 60 and 65 , the average dividends are at $6.46 \%, 6.73 \%$ and $6.82 \%$. All these average values are taken from the historical data declared by EPF Official Website over 30, 35 and 40 years ago [7]. For calculation of monthly retirement benefits, life expectancy at the age of 55, 60 and 65 are used as indicator for post-retirement living which is equal to 24 years, 20 years and 16 years respectively [3]. In accordance to retirement age of 55, 60 and 65, the number of years working is taken as 30,35 and 40 . 
Results are computed in Microsoft Excel using Equation (7) to Equation (8) when growth of retirement fund is included in calculation of upper bound and lower bound of retirement funds when $n=k$.

$$
\begin{array}{r}
F_{n}=\frac{c_{n} \times w_{\text {ave }} \times m \times\left(1+J_{n}\right)^{k-1}}{J_{n}}, \\
F_{n, \text { month }}=\frac{F_{n}}{m \times L_{60}} .
\end{array}
$$

Referring to Equations (7) and (8) for retirement age at 60, modifications are made for retirement age at 55 and 65 . Highest value and lowest value of retirement fund is used as upper bound and lower bound for $F_{n}$ respectively in Inequality (4).

Several assumptions have been made for calculation in Part I and Part II as follows.

1. For contribution rate, retirement age and indexation of pension, lower bound and upper bound are set to be $12 \%$ and $24 \%, 55$ and 65 years, $-10 \%$ and $10 \%$ respectively.

2. The contribution rate is set at either $23 \%$ or $24 \%$ based on average salary.

3. Employment starts at exact age of 25 and ends once retirement age is reached.

4. No unemployment is considered in this study.

5. No re-entering of labour market is considered in this study.

\subsection{Part II: Calculation of Accumulated Retirement Fund of A Fresh Graduate}

In Part II, retirement fund is accumulated from zero until age of retirement is reached. All results are constructed using fresh graduate's salary data from Jobstreet [14]. Initial salary, $w_{1}$ is RM 2,100.00. Values of inflation rate, growth on retirement fund, life expectancy and salary growth are taken as indexation of pension. Three cases in Part II include Case I where no early withdrawal at the age of 50, Case II where there is an early withdrawal at the age of 50 and Case III with $1 \%$ increment of contribution rate to $24 \%$.

Generalised Reduced Gradient (GRG) algorithm is used to verify the optimal values for retirement fund, contribution rate and retirement age based on relevant indexation of pensions. GRG is used via Excel Solver in Microsoft Excel.

The steps for calculation are as follows.

1. Future value and present value for retirement funds as well as monthly retirement benefits are computed. 
2. Microsoft Excel is used for step-by-step calculation for Equation (9) to Equation (21).

$$
\begin{aligned}
& W_{n}=m \times w_{1}\left(1+g_{n}\right)^{n-1}, \\
& F_{n-1}^{*}=F_{n-1} \times\left(1+J_{n}\right), \\
& C_{n}=c_{n} \times W_{n}\left(g_{n}, x_{n, r}\right), \\
& B_{n}=30 \% \times F_{n}, n=26(x=50) \text {, } \\
& F_{n}=F_{n-1}^{*}+C_{n}-B_{n}, \\
& F_{n}=\left(1+J_{n}\right) F_{n-1}+c_{n} W_{n}\left(g_{n}, x_{n, r}\right)-B_{n}\left(x_{n, r}\right) \text {, } \\
& \max _{c_{n}, x_{n, r}, \lambda_{n}} \frac{F_{n}\left(c_{n}, g_{n}, x_{n, r}, \lambda_{n}, J_{n}\right)}{(1+\delta)^{n}}, \\
& F_{n, F V, \text { year }}=\frac{F_{n}}{L_{x^{*}}}, x^{*}=55,60 \text { or } 65 \text {, } \\
& F_{n, F V, \text { month }}=\frac{F_{n, F V, \text { year }}}{m}, \\
& F_{n, P V, \text { year }}=\frac{F_{n}}{(1+\delta)^{n}\left(L_{x^{*}}\right)}, x^{*}=55,60 \text { or } 65, \\
& F_{n, P V, \text { month }}=\frac{F_{n, P V, \text { year }}}{m}, \\
& \text { Percentage }=\frac{F_{F V, n, \text { month }}}{w_{n}} \times 100 \% \text {, } \\
& w_{n}=\frac{W_{n}}{m},
\end{aligned}
$$

where $w_{n}$ is defined as monthly salary, $W_{n}$ as annual salary, $F_{n-1}^{*}$ as amount of previous fund, $C_{n}$ as amount of contribution made, $B_{n}$ as withdrawal made. $F_{n, F V \text {,year }}$ is the future value of retirement benefits (in year), $F_{n, F V \text {, month }}$ is the future value of retirement benefits (in month), $F_{n, P V \text {,year }}$ is the present value of retirement benefits (in year) and $F_{n, P V \text {, month }}$ is the present value of retirement benefits (in month).

3. Results obtained is fitted into Generalised Reduced Gradient (GRG) algorithm in Excel Solver for verification.

4. After retirement fund is found for retirement age between 55 to 65 , two-third retirement decision model is applied based on step (a) to (c).

(a) Percentage of monthly retirement benefits over last drawn salary is found.

(b) Two-third retirement decision model is used to compare with the percentage value in Step 1.

(c) Parameters that fulfil Equation (5) is the optimal paths for sustainable retirement funds in Malaysia.

5. Or else, comparison between present value of monthly retirement benefits and monthly household expenditure is made.

Followings are extra assumptions in Part II.

1. Contribution rate is assumed and taken as $23 \%$.

2. Growth of retirement fund, $J_{n}$ is $6.73 \%$ for all cases in Part II [7].

3. Salary growth, $g_{n}$ is taken as $5.3 \%$, based on compounded annual growth rate (CAGR) [4].

4. Inflation rate, $\delta$ is taken as $3.2 \%$ according to CPI in year 2017 [6].

5. For Case I and Case III, no withdrawal is made until age of retirement is reached. For Case II, full withdrawal is made from Account 2 at the beginning age of 50.

\section{Application to EPF}

Applying formula in Section 2 and 3, we obtain results as in Figure 1 and Figure 2. 


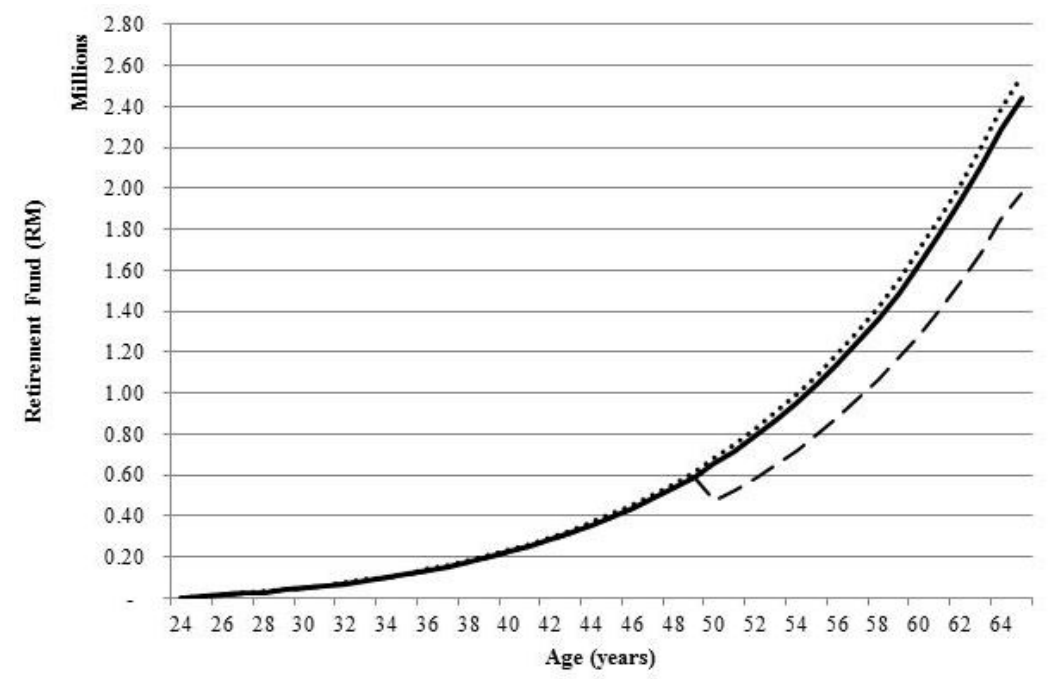

Figure 1. Retirement funds at different ages. Solid curve represents Case I, dashed curve represents Case II and dotted curve represents Case III.

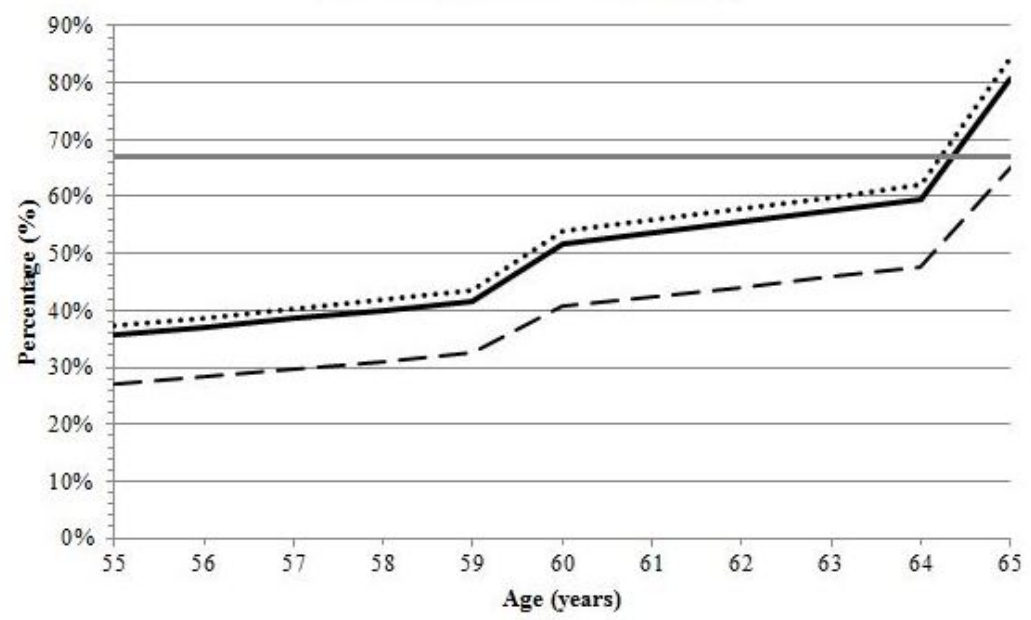

Figure 2. Percentages of monthly retirement benefits over last drawn salary. Solid black line represents Case I, dashed line represents Case II and dotted line represents Case III. Solid grey line is the two-third replacement ratio for decision model.

Considering contribution rate of $23 \%$, results show that when there is no early withdrawal, only retirement at the age of 65 fulfils the two-third retirement decision model and hence, it gives better retirement benefits than retirement at the age of 60 . Same goes to contribution rate of $24 \%$ (Case III). Nevertheless, when there is an early withdrawal case (Case II), retirement decision model is not fulfiled for retirement at the age of 65 . Also, retirement at age of 55 is not being encouraged for all cases as it cannot provide sufficient retirement benefits to daily expenses of retirees. In addition, retirement at age of 60 could be considered if monthly retirement benefits could cover up an retiree's expenses although two-third retirement decision model is violated. This can be justified based on present value of monthly retirement benefits to current monthly household expenditure.

In Case III, the 1\% increment does not affect the percentage of monthly retirement benefits over last drawn salary in a large scale. If further increments are made, it is found that retirement at the age of 60 is possible based on two-third retirement decision model when the contribution made is up to $30 \%$ of monthly wages. 
Figure 3 shows the working of GRG model using Excel Solver for the case when $c_{n}=23 \%$. Similarly, GRG model gives retirement fund at the age of 60 equals to RM 1,660,129.11 with $c_{n}=24 \%$ with beginning salary of RM 2,100.

Part II: Solving via Generalised Reduced Gradient (GRG) Algorithm

Input Parameters
\begin{tabular}{|llr|}
\hline Age enter workforce & & 25 \\
Initial salary per month & w_0 & $2,100.00$ \\
Salary growth & g_n & $5.30 \%$ \\
Return on Investment & J_n & $6.73 \%$ \\
Contribution rate & c_n & $23.00 \%$ \\
Number of month & & 12 \\
Expected Life Expectancy & at birth & 75 \\
& at age of 55 & 24 \\
& at age of 60 & 20 \\
& at age of 65 & 16 \\
Discount rate & $\delta$ & $3.20 \%$ \\
\hline
\end{tabular}

\begin{tabular}{|c|c|c|c|c|c|}
\hline \multicolumn{6}{|l|}{ Optimal Solution: } \\
\hline Retirement Fund at age of 60 & $1,590,957.06$ & & & & \\
\hline \multicolumn{6}{|l|}{ Constraints: } \\
\hline Contribution rate & 0.12 & $<=$ & c_n & $<=$ & 0.23 \\
\hline Retirement age & 55 & $<=$ & $x_{-} r$ & $<=$ & 60 \\
\hline Contribution rate & 0.23 & & 0.23 & $<=$ & $23 \%$ \\
\hline Retirement age & 60 & & 60 & $<=$ & 60 \\
\hline
\end{tabular}

Figure 3. Workings of GRG for Case I. This shows the total retirement fund at the age of 60 is RM $1,590,957.06$ with $c_{n}=23 \%$ with beginning salary of RM 2,100.

\section{Concluding Remarks}

We have introduced a new method to analyse the sustainability of EPF retirement savings in Malaysia. We use two-third replacement ratio to fit into DC retirement systems. It is found that retirement benefits for retirement age at 65 with a contribution rate of $23 \%$ can cover up more than $67 \%$ of a person last-drawn salary based on relevant indexation of pension. Even though mathematical results support retirement at the age of 65 based on two-third replacement ratio, retirement decision should be made with fair judgment of other personal factors, such as health condition, monthly expenditure and living standard instead of monetary value of retirement benefits. Also, negative consequences will come along for late retirement in the market. Therefore, it is advisable to involve in other retirement planning instead of solely EPF for an earlier retirement age.

The drawback of the model proposed here is that a constant salary growth is used for the entire career life. It seems impossible as there is always an extra increment of salary when there is a promotion in job. Thus, a more detailed salary portfolio is required. Moreover, if the scope of research is based on private sector, it would be preferable to obtain relevant data for purely private sector only.

Funding: This research received no external funding.

Conflicts of Interest: The authors declare no conflict of interest.

Author Contributions: Both authors contributed equally in the development of the manuscript.

\section{References}

1. N. Barr and P. Diamond, Reforming Pensions: Principles, Analytical Errors and Policy Directions, International Social Security Review 62 (2009), 9 no. 2, 1-3. 
2. Department of Statistics Malaysia, Abridged life tables, Malaysia, 2013

3. Department of Statistics Malaysia, The office of Chief Statistician Malaysia, 2016.

4. Department of Statistics Malaysia, Selected demographic estimates Malaysia 2016, The Office of Chief Statistician Malaysia, October 2016.

5. Department of Statistics Malaysia, Consumer price index Malaysia January 2017, The Office of Chief Statistician Malaysia, 2017.

6. Department of Statistics Malaysia, Salaries and wages survey report Malaysia 2016, The Office of Chief Statistician Malaysia, 2017.

7. EPF official Website, Dividend rates, KWSP EPF, 2017.

8. European Comission, An agenda for adequate, safe and sustainable pensions, White Paper, February 2012, p. 9.

9. F. Gannon, F. Legros, and V. Touze, Automatic Adjustment Mechanisms and Budget Balancing of Pensions Schemes, Working Paper, OFCE, vol. 24, 2014, pp. 13-15.

10. H. Godinez-Olivares, M. C. Boado-Penas, and S. Haberman, Optimal strategies for pay-as-you-go pension finance: A sustainability framework, Journal of Insurance: Mathematics and Economics 69 (2016), 117-126.

11. H. Godinez-Olivares, M.C. Boado-Penas, and A. A. Pantelous, How to Finance Pensions: Optimal Strategies for Pay-As-You-Go Pension Systems, Journal Forecast 35 (2015), no. 1, 13-33.

12. S. Haberman and A. Zimbidis, An Investigation of the Pay-As-You-Go Financing Method using a Contingency Fund and Optimal Control Techniques, North American Actuarial Journal 6 (2002), no. 2, 60-75.

13. iMoney Malaysia, Top 10 highest paying jobs in Malaysia, iMoney.com, 2016.

14. Jobstreet, Fresh graduate salary guide 2016/2017, Jobstreet.com, 2016.

15. M. Knell, W. Kohler-Toglhofer, and D. Prammer, The Austrain Pension System - How Recent Reforms have Changed Fiscal Sustainability and Pension Benets, Monetary Policy and The Economy Q 2 (2006), 69-93.

16. B. J. MacDonald and A. J. G. Cairns, Three Retirement Decision Models for Defined Contribution Pension Plan Members: A Simulation Study, Journal of Insurance: Mathematics and Economics 48 (2011), no. 1, 1-18.

17. Occasional Studies, Fiscal sustainability report, Konjunktur Institutet, 2016, No. 47.

18. A. Pantelous and A. Zimbidis, A Quasi Pay-As-You-Go Financing Method For Controlling The International Demographic Phenomenon of Aging Population, Proceedings of the 19th Conference of Hellenic Institute of Statistics, Kastoria, Greece, 2006, pp. 657-665.

19. Dynamic Reforming of A Quasi Pay-As-You-Go Social Security System within Discrete Stochastic Multidimensional Framework Using Optimal Control Methods, Applicationes Mathematicae 35 (2008), 121-144.

20. A. Yeoh, Retirement Planning: Differences between Private Retirement Scheme (PRS) and Deferred Annuity, Financial 1st 1 (2015), 32-33. 
Biodata of the Authors

Sim Ying Run was born in Alor Setar. She had enrolled Bachelor Degree in Universiti Putra Malaysia (UPM). She obtained a Bachelor of Science (Honours) Major in Mathematics. She is planning to continue to further her postgraduate studies.

Adem Kilicman serves as a Full Professor at the Department of Mathematics, Faculty of Science, University Putra, Serdang, Selangor, Malaysia. He received his BSc. and MSc. degrees from the Department of Mathematics, Hacettepe University, Turkey, and obtained Ph.D. degree from the University of Leicester, UK in 1995. He has joined the University Putra, Malaysia, in 1997. Since then, he has been working at the Faculty of Science, and he is also an active member of the Institute for Mathematical Research, University Putra, Malaysia. Prof. Kilicman has managed to publish several research papers in international repute journals and members of several Associations including American and European Mathematical Societies. 